Escuela de Ciencias Sociales y Humanidades, UNED, C.R. URL: http://investiga.uned.ac.cr/revistas/index.php/espiga/index ISSN: 1409-4002 • e-ISSN: 2215-454X

\title{
La trata de personas con fines de explotación sexual en España: elementos para la reflexión
}

\author{
Belén Blázquez-Vilaplana* \\ (D) https://orcid.org/0000-0003-0440-9113
}

Recibido: 30 de mayo, 2017 - Aceptado: 27 de setiembre, 2017

\section{RESUMEN}

Aunque la legislación española no reconoce como violencia de género la Trata de Personas con Fines de Explotación Sexual, lo cierto es que desde distintas instancias se está trabajando para su modificación en línea con los acuerdos internacionales firmados y ratificados por el Gobierno español y con las voces que se han alzado desde la sociedad civil. Su estrecha relación con la prostitución, su confusión con el tráfico ilícito de personas y el baile de datos que existe para su cuantificación, lo han convertido en un fenómeno que muchos dicen desconocer pero que alcanza importantes cotas de presencia en el territorio. Visibilizar este fenómeno y abrir espacios para la reflexión son los objetivos de este trabajo.

Palabras clave: prostitución, esclavitud, abuso sexual, España.

\section{Formato de citación según APA}

Blázquez, B. (2017). La trata de personas con fines de explotación sexual en España: elementos para la reflexión. Revista Espiga 16(34), 183-196. Doi: http://dx.doi. org/10.22458/re.v17i34.1795

\section{Formato de citación según Chicago-Deusto}

Blázquez, Belén. «La trata de personas con fines de explotación sexual en España: elementos para la reflexión». Revista Espiga, 16, n. ${ }^{\circ} 34$ (julio-diciembre, 2017): 183-196. Doi: http://dx.doi.org/10.22458/re.v17i34.1795

* Profesora titular del área de Ciencia Política y de la Administración de la Universidad de Jaén (España). Doctora en Ciencia Política y de la Administración por la Universidad de Granada. Maestría en Teoría Crítica y del Derecho en Iberoamérica (UNIA-La Rábida-España). Especialista en estudios de género. Docente en grado y posgrado relacionados con los estudios de género y la Ciencia Política y de la Administración. Universidad de Jaén. España. Correo: bblazquez@ujaen.es 


\section{Introducción}

El 15 de noviembre de 2016, el Congreso de los Diputados español aprobaba por unanimidad la Proposición No de Ley presentada por el Partido Popular (PP) y el Partido Socialista Obrero Español (PSOE) para sentar las bases de la realización de un Pacto de Estado que debía luchar contra la violencia de género. En dicho Pacto deberían estar involucrados tanto el gobierno central como las comunidades autónomas y las entidades locales. Dicha propuesta ha dado paso a la creación de una subcomisión dentro del Congreso, en el seno de la Comisión de Igualdad, cuyo fin será la realización de un informe en el que se analicen los problemas que han impedido que la Ley Orgánica 1/2004, del 28 de diciembre, de medidas de protección integral contra la Violencia de Género ${ }^{1}$ haya conseguido acabar con esta lacra social.Una de las modificaciones propuestas es ampliar el concepto de violencia de género dentro de la legislación española para incluir, entre otros delitos, la trata de personas con fines de explotación sexual. Este hecho va a servir como punto de partida para reflexionar y visibilizar este fenómeno. La necesidad de estos cambios es consecuencia directa de las distintas normativas internacionales a las que España se ha adherido desde la aprobación de la mencionada Ley Orgánica en el 2004. Entre ellas se tendrían que mencionar dos por su importancia: a) la aplicación del Convenio de Estambul ${ }^{2}$ que había ratificado el 27 de mayo de $2014^{3}$ y entrado en vigor el 1 de agosto del mismo año y b) el conocido como Protocolo de Palermo ${ }^{5}$. Estas dos normativas son las más significativas pero no las únicas que regulan y tratan de controlar y sancionar la trata de personas con fines de explotación sexual en territorio español. En este sentido, en la actualidad, aunque está tipificado como delito penal por cuanto es una clara violación de los derechos humanos y una execrable forma de ejercer la violencia, sobre todo hacia las mujeres ${ }^{6}$, no se le aplicarían las medidas derivadas de ser considerado

1. Boletín Oficial del Estado, n. ${ }^{\circ} 313,29$ de diciembre, 2004.

2. Convenio del Consejo de Europa sobre prevención y lucha contra la violencia contra las mujeres y la violencia doméstica.

3. Boletín Oficial del Estado n. ${ }^{\circ}$ 137, 6 de junio, 2014.

4. Anteriormente también se había adherido a la Resolución 2005/41 de la Oficina del Alto Comisionado de las Naciones Unidas para los Derechos Humanos, para la cual la violencia contra la mujer se entiende como «todo acto de violencia sexista que tenga o pueda tener como resultado un daño o sufrimiento físico, sexual o psicológico para la mujer, así como las amenazas de tales actos, la coacción o la privación arbitraria de la libertad, tanto si se producen en la vida pública como en la vida privada, y que abarca, sin limitarse a estos actos, la violencia doméstica, los delitos cometidos por cuestiones de honor, los crímenes pasionales, la trata de mujeres y niñas, las prácticas tradicionales nocivas para la mujer y la niña, incluida la mutilación genital femenina, el matrimonio precoz y forzado, el infanticidio de niñas, los actos de violencia y los asesinatos relacionados con la dote, los ataques con ácido y la violencia relacionada con la explotación sexual comercial y con la explotación económica».

5. En él, el concepto de trata es entendido como «la captación, transporte, traslado, acogida o recepción de personas, recurriendo a la amenaza o al uso de la fuerza u otras formas de coacción, al rapto, al fraude, al engaño, al abuso de poder o de una situación de vulnerabilidad o a la concesión o recepción de pagos o beneficios para obtener el consentimiento de una persona que tenga autoridad sobre otra, con fines de explotación. Esa explotación incluirá, como mínimo, la explotación de la prostitución ajena u otras formas de explotación sexual, trabajos o servicios forzados, la esclavitud o las prácticas análogas a la esclavitud, la servidumbre o la extracción de órganos». Para mayor información véase: Protocolo para Prevenir, Reprimir y Sancionar la trata de personas que complementa la Convención de Naciones Unidas contra la Delincuencia Organizada Transnacional. BOE n. ${ }^{\circ} 296,11$ de diciembre, 2003.

6. Las distintas estadísticas nacionales e internacionales indican que más del $90 \%$ de las personas que sufren trata para explotación sexual son mujeres y niñas. 
un caso de "violencia de género". Ello porque para el legislador español solo estaríamos ante un caso de violencia de género ${ }^{7}$, según el artículo 1 de la Ley Orgánica 1/2004 ya referida, cuando esta se ejerce sobre las mujeres por parte de aquellos que han sido o son sus cónyuges o quienes hayan estado o estén ligados a ellas por relaciones similares de afectividad, aún sin convivencia. Siendo consecuencia de «la manifestación de la discriminación, la situación de desigualdad y las relaciones de poder de los hombres sobre las mujeres (...) comprendiendo todo acto de violencia física y psicológica, incluidas las agresiones a la libertad sexual, las amenazas, las coacciones o la privación arbitraria de libertad $»^{8}$. Por tanto, esa no consideración de la trata como violencia de género, a pesar de que de la lectura de su definición - excepto el caso de relación afectiva- hace pensar en su innegable y directa relación con lo recogido en el Protocolo de Palermo, impide aplicar las medidas de protección integral que se vienen implementando en España. De este modo, considerar la trata como violencia de género supondría un plus de protección y garantías para las víctimas, al reconocerlo como un agravante porque haría que dicho delito se entendiera que viene definido por la situación de explotación y servidumbre en que se sitúan las mujeres y las niñas en relación con los hombres por el simple hecho de ser mujeres. Permitiendo, de este modo, sancionar e imponer especiales medidas cautelares y de aseguramiento de las víctimas ${ }^{9}$. Además, si finalmente se definiera la trata de personas con fines de explotación sexual como violencia de género, se podría superar el vacío legislativo actual derivado de la inexistencia de una ley integral.

España se ha convertido en país de origen, de paso y de llegada de este delito trasnacional. Este último factor, la transnacionalidad, es determinante para trabajar en la consecución de medidas para prevenir y luchar contra la trata; puesto que en ningún caso es posible analizarla solo como un fenómeno que se circunscriba a lo que ocurre dentro de las fronteras nacionales. Actualmente, los acuerdos y tratados internacionales para luchar contra la trata se han plasmado en territorio español, no en una ley integral, sino en dos Planes de Lucha Integral contra la Trata de Personas con Fines de Explotación Sexual: uno de ellos ya finalizado, 2009-2012 ${ }^{10}$, y otro en proceso de implementación, 20152018. Necesarios pero insuficientes si se considera que, como se acaba de mencionar, España se ha convertido tanto en país de tránsito en el delito de la trata como también

7. En España no se utiliza el término feminicidio.

8. Ley Orgánica 1/2004, de 28 de diciembre de Medidas de Protección Integral contra la Violencia de Género, artículo 1.

9. En el caso de la normativa española, si existe una denuncia por violencia de género, se ponen en marcha una serie de medidas que no se contemplan en otras situaciones de violencia hacia las mujeres, violencia doméstica o violencia familiar. Por ejemplo, se detiene inmediatamente al agresor por un período de 72 horas y se realiza un juicio rápido en los Juzgados de violencia sobre la mujer. A partir de ahí, se pueden interponer medidas contra el agresor y a favor de la víctima que guardan relación con el abandono del domicilio familiar, si lo hubiera; con la guarda y custodia de los menores; con una orden de alejamiento, etcétera.

10. Sobre este Primer Plan existen cuatro informes de seguimiento y un Informe Final. Para poder conocer su contenido véase: Delegación del Gobierno para la Violencia de Género, Ministerio de Sanidad, Servicios Sociales e Igualdad. Acceso: 16 de marzo, 2017. http://www.violenciagenero.msssi.gob.es/otrasFormas/ trata/normativaProtocolo/informes/home.htm 
en país de captación y de explotación de mujeres y niñas ${ }^{11}$. Hoy tiene el dudoso honor de encontrarse en los primeros lugares en relación con la existencia de este fenómeno en su territorio. Pero, además, también ocupa los puestos más altos en aquellas escalas que lo que analizan, desligado de la trata -si es que es posible hacerlo-, en el consumo de la prostitución ${ }^{12}$. No por menos, según datos del Instituto Nacional de Estadística (INE), la prostitución supone en España el 0.35\% del Producto Interior Bruto, unos 3700 millones de euros al año ${ }^{13}$.

El objetivo de este análisis es dar a conocer un fenómeno que para muchos sigue oculto, el de la Trata de Personas con Fines de Explotación Sexual en España, a pesar de la importante presencia que tiene dentro de sus fronteras. Lo cierto es que no existen datos oficiales y los que se proporcionan por diversos organismos nacionales e internacionales no siempre coinciden entre si $^{14}$. Se estima que en Europa hay unas 500000 víctimas de trata, de las cuales, 45000 se encontrarían en España ${ }^{15}$, para mover un total de 5 millones de euros al día, siendo el segundo negocio más rentable del mundo tras el tráfico de drogas y junto al tráfico de armas. El baile de datos, que es frecuentemente denunciado tanto por organizaciones no gubernamentales que intentan luchar contra la trata, como por aquellas personas que quieren acercarse mediante sus investigaciones a su análisis; es el más claro reflejo de la dificultad que aún hoy existe para enfrentarse a él ${ }^{16}$. Se está ante

11. Los datos dicen que en el 2015 se pudieron detectar a 48 menores de edad víctimas de la trata. Existe un estudio muy interesante sobre cuántas de estas personas que sufren trata con fines de explotación sexual son menores: UNICEF: Son niños y niñas, son víctimas. Situación de los menores de edad víctimas de trata en España. Acceso: 15 de febrero, 2017. https://www.unicef.es/sites/unicef.es/files/comunicacion/ninosvictimas.pdf, 2017.

12. Un $20 \%$ de los hombres en España reconocen haber pagado recientemente por servicios de prostitución y la mayoría no conciben que la mujer que los prestaba podía ser objeto de Trata. Además, el 10\% detectó que entre esas mujeres había menores de edad, pero no hicieron nada por denunciarlo. Para mayor información véase Carmen Meneses Falcón, et al, Apoyando a las víctimas de Trata. Las necesidades de las mujeres víctimas de trata con fines de explotación sexual desde la perspectiva de las entidades especializadas y profesionales involucrados. Propuesta a la sensibilización de la Trata. (Madrid: Delegación del Gobierno para la Violencia de Género. Ministerio de Sanidad, Servicios Sociales e Igualdad. 2015).

13. Europa Press. «¿Es legal la prostitución en España? Situación de la prostitución en España». Otros datos utilizados por la Comisión del Congreso sobre la prostitución en 2007 hablaban de que este negocio movía más de 18000 millones de euros cada año en España, mientras que desde la Policía Nacional calculaban que podrían ser más de 1825 millones de euros al año. Acceso: 8 de enero, 2017. http://www.europapress. es/sociedad/noticia-situacion-prostitucion-espana-20150421141927.html

14. Para profundizar en las dificultades que existen a la hora de investigar sobre la trata de personas puede verse: Laura Requena Espada, Andrea Giménez -Salinas Framis y Manuel de Juan Espinosa. «Estudiar la Trata de Personas. Problemas metodológicos y propuestas para su resolución». Revista Electrónica de Ciencia Penal y Criminológica. 14-13 (2012). Acceso: 10 de febrero, 2017. http://criminet.ugr.es/recpc/14/ recpc14-13.pdf

15. Cada año entran en Europa unas 100.000 mujeres y niñas. II Plan contra la Trata de Personas con Fines de Explotación Sexual, 2015-2018. Gobierno de España. Acceso: 19 de enero, 2017. http://www.violenciagenero.msssi.gob.es/planActuacion/planContraExplotacionSexual/docs/Plan_Integral_Trata_18_ Septiembre2015_2018.pdf

16. Begoña Marugán Pintos, miembro del equipo del Proyecto THB:COOPtoFight afirmaba que «estadísticamente se desconoce la dimensión del problema: por su naturaleza delictiva, ilegal y transnacional; por su confusa definición; por la escasa legislación (se tipifica en el Código Penal en 2010); y por las escasas herramientas de recogida de la información de que disponemos». Dicho equipo elaboró el Informe: The fight against trafficking in human beings in EU: promoting legal cooperation and victims' protection. Acceso: 22 de marzo, 2017. http://e-archivo.uc3m.es/handle/10016/19399\#preview 
un fenómeno a nivel mundial, clandestino, ilegal, transnacional, controlado por mafias y enormemente lucrativo.

Conseguir que la trata de personas con fines de explotación sexual entrara en la agenda gubernamental, como pone de manifiesto la existencia de los dos Planes mencionados y de otras medidas implementadas en territorio español, no ha supuesto, sin embargo, que las personas que la sufren dejen de hacerlo. La lucha contra la trata y, por ende, contra la violencia de género que subyace a ella, sigue siendo una de las eternas reivindicaciones de los movimientos feministas en España. En el presente trabajo se busca sacar de la oscuridad un tema que todo el mundo sabe que existe pero que a muchos les cuesta reconocer. Aportar algunos elementos al debate que permitan entender por qué en la actualidad se sigue consintiendo esta violación de los derechos humanos más fundamentales, el de la integridad física y moral de tantas mujeres y niñas bajo la aparente permisividad que existe entre la población española con el comercio sexual. Las continuas campañas y denuncias que se vienen haciendo sobre este tema han empezado, o así se pensaba, a calar entre la ciudadanía; pero los datos que se manejan sobre la prostitución dicen lo contrario. Tras las afirmaciones que intentan justificar la legalización de la prostitución y del libre uso de su cuerpo por las mujeres se esconde una terrible realidad. Según datos del Ministerio del Interior, tras los cambios legislativos del 2010 y hasta el 2016, más de 4300 mujeres habían sido víctimas de esta lacra ${ }^{17}$. Mientras haya demanda seguirá existiendo una oferta que la satisfaga y, en este sentido, las mujeres y niñas objetos -en el sentido más literal de la palabra- de la trata son consideradas mercancías. En pleno siglo XXI, donde todo se puede comprar y vender, el cuerpo de las mujeres es un negocio muy rentable, porque a diferencia de las drogas y/o las armas, solo es necesario «lavarlo para volverlo a usar». La trata no es solo violencia hacia las mujeres, sino violencia de género por cuanto es imposible entender este fenómeno sin enmarcarlo en la cultura patriarcal de dominación y sometimiento que despliega el hombre hacia la mujer. Siendo un claro ejemplo del ejercicio del poder asociado a los roles. Es imposible acabar con este problema social si no se analiza desde una perspectiva de género, porque el género es el elemento diferenciador de otros muchos tipos de violencias que existen y persisten en este siglo. La trata no se puede entender si no se asocia y se analiza como se hace con la feminización de la pobreza; con las situaciones de especial vulnerabilidad a las que están sometidas las mujeres; con la explotación laboral y sexual que sufren en gran parte del mundo; etcétera.

17. Iñigo Domínguez y José María Jiménez Gálvez,«Esclavos en España en el Siglo XXI». Diario El País, Reportajes Especiales. «En un informe del Centro de Inteligencia contra el Terrorismo y el Crimen Organizado (CITCO) del Ministerio del Interior (...) se revela lo invisible que está ante nuestros ojos. Y es brutal: 4430 víctimas de trata y explotación sexual, o solo de este segundo delito, de 2012 a 2016. Si se suman las de explotación laboral, perseguida con más ahínco desde 2015, ascienden a 5675 personas. Y 20 más son de otros tipos de trata. Solo en 2016, el dato más reciente, el total de víctimas suma 1046». Acceso: 25 de abril, 2017.http://elpais.com/agr/esclavos_en_espana_en_el_siglo_xxi/a/ 


\section{Desarrollo}

En España, históricamente, la violencia de género se había considerado un tema que no tenía que ser objeto de atención por los poderes públicos. Es decir, se era consciente de que esta existía, pero se encubría bajo la catalogación de «parricidio» y/o «crimen pasional» ${ }^{18}$. Las cosas comenzaron a cambiar a finales del siglo pasado. Un desgraciado suceso ${ }^{19}$ dio lugar a que entrara en la agenda pública de las distintas fuerzas políticas con representación parlamentaria y terminara en el 2004 con la aprobación de la Ley Orgánica 1/2004, del 28 de diciembre, de Medidas de Protección Integral contra la Violencia de Género ${ }^{20}$. Sin embargo, este hecho tan aplaudido delimitó el concepto de violencia de género tal y como se ha referido anteriormente. La consecuencia directa de ello fue que la trata de personas con fines de explotación sexual quedó lejos de estar bajo el amparo de dicha normativa y, por tanto, de su especial protección y atención.

Esto no quiere decir que los poderes públicos hayan dejado este tema fuera de sus agendas gubernamentales. Pero los pasos dados han sido lentos y en muchos casos insuficientes. En este sentido, la llamada «Esclavitud del Siglo XXI» ha seguido siendo un fenómeno silenciado para una parte de la sociedad española. Como afirmaba el Ministro de Sanidad en la presentación del II Plan contra la Trata de Personas con Fines de Explotación Sexual, «es un problema que lo tenemos en casa, lo tenemos oculto, a veces entre luces de neón, y no podemos mirar hacia otro lado ${ }^{21}$. Su estrecha interconexión con la prostitución; la dificultad para cuantificar el número de personas que son explotadas por las mafias y redes de tratantes y en muchos casos el abordaje institucional conjunto del tema de la trata con el del tráfico ilegal de personas ${ }^{22}$, ha conllevado que España sea catalogada como un paraíso para este fenómeno a nivel internacional, tras Tailandia, Brasil y Puerto Rico. A pesar de los avances - que los ha habido- aún se percibe a este delito como impune y como un negocio próspero y con futuro en territorio español. España es una puerta de entrada fácil al continente europeo, ya sea a través de sus aeropuertos internacionales o por la frontera del mar Mediterráneo. Lo cierto es que no se puede analizar la trata de personas con fines de explotación sexual sin dejar de tener en cuenta la situación geopolítica española.

18. Para mayor información véase: Miguel Lorente Acosta, Mi marido me pega lo normal (Barcelona: Crítica, 2003); Nuria Varela, Íbamos a ser reinas: mentiras y complicidades que sustentan la violencia contra las mujeres (Barcelona: Ediciones B, 2002) y La voz ignorada. Ana Orantes y el fin de la Impunidad (Colección Endebate, 2012).

19. En 1997 Ana Orantes aparecía en un programa de televisión contando las continuas palizas y vejaciones que había sufrido por parte de su marido durante toda su vida. Vivían aún en la misma casa, cada uno de ellos en una planta, porque aunque se habían divorciado el juez había decidido que compartieran el domicilio conyugal. Días después de acudir a dicho programa, el marido la acorraló en el patio de la casa, la roció con gasolina y le prendió fuego. Ese asesinato fue el comienzo de la consideración de la violencia de género como problema público en España.

20. Boletín Oficial del Estado, n. ${ }^{\circ} 313$, de 29 de diciembre, 2004.

21. Alejandro Torres Reyes, «Unas 45000 mujeres y niñas son víctimas de trata en España». Diario El País. 18 de septiembre, 2015. Acceso: 15 de febrero, 2017. http://politica.elpais.com/politica/2015/09/18/actualidad/1442572111_462915.html

22. Laura Nuño Gómez, «La Trata de Seres Humanos con Fines de Explotación Sexual: Propuestas para un cambio de paradigma en la orientación de las Políticas Públicas». Revista de Derecho Politico. UNED. n. ${ }^{\circ}$ 98, enero-abril, 2017: 159-187. 
Los datos afirman que en la actualidad España es el país de Europa donde se han detectado un mayor número de casos de explotación sexual y, a nivel internacional, se la considera como la «Tailandia europea» ${ }^{23}$. No es posible entender este hecho sin dar algunos datos acerca del funcionamiento de la llamada «industria del sexo». En primer lugar, en España la prostitución es alegal, la legislación solo castiga al proxeneta siempre y cuando se pueda demostrar que lo es, no al cliente ni a la prostituta. Solo tras la entrada en vigor de la ley conocida como "Ley Mordaza» 24 , se han podido multar a algunos puteros por situarse cerca de colegios, parques infantiles o de ocio o por poner en riesgo la seguridad vial. Pero también a algunas meretrices por «actos de exhibición obscena» y, en la mayor parte de los casos, por oponerse a la autoridad. Según indica la profesora María Luisa Maqueda, «la ley es canalla, es un avance brutal del Estado más autoritario. Una estrategia perfectamente trazada que no repara en el daño e indefensión de las trabajadoras del sexo. El efecto es la clandestinidad y que estén muy acosadas. Presentan problemas con la custodia de los niños, pero sobre todo de defensa contra los clientes» ${ }^{25}$. En este sentido, la Asociación para la Prevención, Reinserción y Atención a la Mujer Prostituida (APRAMP) denunció que la entrada en vigor de esta Ley sólo solo iba a aumentar la dificultad de las mujeres que se prostituían para salir de las redes mafiosas que las explotaban. El aumento de la deuda contraída para llegar a España y su desplazamiento de los polígonos a zonas donde no sean tan visibilizadas (clubes de alternes), les impide poder salir de la situación en la que se encuentran y aumenta su inseguridad. Además, en palabras de Valentín Márquez, coordinador de proyectos de inclusión social en Andalucía para Médicos del Mundo, la ley les lleva a identificar «al Policía como un enemigo y no como un colaborador» ${ }^{26}$. En los últimos recuentos «extraoficiales»se han podido contabilizar más de 1900 clubes de alternes. Siendo los que se encuentran en La Junquera, en la frontera con Francia, los que conforman el mayor prostíbulo de Europa con más de 200 mujeres entre su oferta. Además de esa variada oferta, los precios son competitivos, existen garantías sanitarias y los entornos se consideran seguros. Un paraíso para este tipo de delitos.

En segundo lugar, en la actualidad son muchos los hombres que consideran que «irse de putas» es una forma de ocio, de celebrar un ascenso o un buen día en la oficina, de desconectar un fin de semana o, en los últimos años, un final de fiesta para las despedidas de soltero ${ }^{27}$. Además, como afirma Laura Nuño, «el turismo sexual, es un reclamo

23. Para un análisis pormenorizado de los datos existentes, véase: Gobierno de España. Plan Integral de lucha contra la trata de personas con fines de explotación sexual 2015-2018. Ministerio de Sanidad, Servicios Sociales e Igualdad, 2016. Acceso: 12 febrero, 2018. http://www.interior.gob.es/documents/642012/5707784/ Plan+Integral+Trata+2015/f74fd062-48ce-47d4-bedf-aae0ce2a0509

24. Ley Orgánica 4/2015, de 30 de marzo, de protección de la seguridad ciudadana.

25. Javier Martín-Arroyo, «Denunciados un millar de prostitutas y clientes tras un año de la "Ley Mordaza"». Diario El País. Acceso: 20 de febrero, 2017. http://politica.elpais.com/politica/2016/09/02/ actualidad/1472839814_078043.html

26. Teo Fuentes y Gino Ochoa, «La Ley Mordaza olvida que las prostitutas también son personas». Diagonal Periódico, 28 de agosto, 2015. Acceso: 14 de enero, 2017. https://www.diagonalperiodico.net/ andalucia/27601-la-ley-mordaza-se-olvida-prostitutas-tambien-son-ciudadanas.html

27. Existe un estudio muy interesante sobre los hombres que usan la prostitución en España: Águeda Gómez Suárez, Silvia Pérez Freire y Rosa María Verdugo Matés. El putero español. Quiénes son y qué buscan los clientes de la prostitución. (Madrid: Catarata, 2015). 
habitual en los folletos de las agencias de viajes que promocionan nuestro país como destino vacacional y la situación territorial la convierte en una puerta de entrada al espacio Schengen por el sur de Europa ${ }^{28} \gg$. Pero mientras el discurso que se venda sea el de que la prostitución no es un problema porque «quien está ahí es porque quiere», se seguirá mirando hacia otro lado, no se plantearán alternativas para las mujeres que quieren salir de su ejercicio -no se las puede culpar por el miedo que las atenaza a no denunciar ni por el estigma que arrastran en la sociedad- ni se dejará de re victimizar a la mujer que ha sido objeto de la trata. Se seguirá sin ver a todas esas mujeres que están, sin ser vistas y que miramos pero no vemos ${ }^{29}$.

A pesar de todo, como se ha afirmado anteriormente, se han dado algunos pasos para luchar contra ello. En la actualidad, en el territorio español es donde mayor número de operaciones policiales se han llevado a cabo contra este delito. Sobre todo, desde que en el 2010 se modificara el Código Penal ${ }^{30}$, incluyendo el artículo 177 bis, en el cual se tipifica el delito de la trata como:

La captación, el transporte, el traslado, la acogida o la recepción de personas, incluido el intercambio o transferencia de control sobre esas personas, cuando se emplee violencia, intimidación o engaño, o se abuse de una situación de superioridad o de necesidad o vulnerabilidad de una víctima, ya sea nacional o extranjera o cuando medie la entrega o recepción de pagos o beneficios para lograr el consentimiento de la persona que posea el control sobre la víctima, la captare, transportare, trasladare, acogiere, o recibiere, incluido el intercambio o transferencia de control sobre esas personas, con cualquiera de las finalidades siguientes: a) La imposición de trabajo o de servicios forzados; b) la esclavitud o prácticas similares a la esclavitud, a la servidumbre o a la mendicidad; c) La explotación sexual, incluyendo la pornografía; d)La explotación para realizar actividades delictivas; e) La extracción de sus órganos corporales; f) La celebración de matrimonios forzados ${ }^{31}$.

Posteriormente, en el 2015 se volvió a modificar el Código Penal ${ }^{32}$, ampliándose los hechos constitutivos de trata, delimitándose el concepto de vulnerabilidad, regulándose el decomiso de los efectos, bienes, instrumentos y ganancias procedentes de la trata, incorporando el género como motivo de discriminación en la agravante de comisión del delito. Así mismo, la modificación del artículo 318 bis redujo la sanción por tráfico diferenciándola, sustancialmente, de las penas previstas para la Trata de Seres Humanos con Fines de Explotación Sexual.

28. Nuño Gómez, «La trata de seres humanos con fines de explotación sexual: propuestas para un cambio de paradigma en la orientación de las políticas públicas», 175

29. Sobre la libertad de elección, es interesante el trabajo de Ana de Miguel: De Miguel Álvarez. Neoliberalismo sexual: el mito de la libre elección (Valencia: Cátedra, 2015).

30. Ley Orgánica 5/2010, de 22 de junio, por la que se modifica la Ley Orgánica 10/1995, de 23 de noviembre, del Código Penal.

31. Existe un Acuerdo del Pleno no Jurisdiccional de la Sala Segunda del Tribunal Supremo, de 31 de mayo, 2016, aplicado por vez primera en una Sentencia de la Sala de lo Penal del Tribunal Supremo, por el cual se establece que «el delito de trata de seres humanos definido en el artículo 177 bis del Código Penal, reformado por la LO 1/2015, de 30 de marzo, obliga a sancionar tantos delitos como víctimas, con arreglo a las normas que regulan el concurso real».

32. Ley Orgánica 1/2015, de 30 de marzo, por la que se modifica la Ley Orgánica 10/1995, de 23 de noviembre, del Código Penal. 
En palabras de Mabel Lozano, directora del documental «Chicas nuevas 24 horas», «nunca ha valido tan barata una esclava como ahora ${ }^{33}$ ». Aunque no es posible dibujar un único perfil de cuáles mujeres y niñas son objeto de trata con fines de explotación sexual en España, los diversos estudios e investigaciones que se están llevando a cabo por organizaciones no gubernamentales, organismos públicos y universidades, permiten tener conocimiento de algunos rasgos importantes ${ }^{34}$. La mayor parte de estas mujeres proceden de cuatro zonas, a saber: a) países del Este de Europa, sobre todo Rumanía y Bulgaria; b) África Subsahariana, especialmente de Nigeria; c) América Latina, sobre todo Bolivia, Paraguay, Brasil y República Dominicana y d) China. Muchas de ellas llegan con falsas promesas laborales o engañadas por lo que se conoce como el lover boy. En todos los casos adquieren una deuda de una cuantía desorbitante, que aumenta sin parar desde el mismo momento en que salen de sus territorios de origen. Aunque como elemento común a todas se les retira el pasaporte, al tiempo que son consideradas mercancías y se les amenaza, viola y maltrata; por otro, sus distintas nacionalidades las dota de algunos elementos diferenciadores. En el caso de las rumanas y búlgaras, suelen llegar a España por medios terrestres, sin problemas con el pase de las fronteras porque son ciudadanas europeas y pueden depender de un proxeneta que se encuentre en territorio español o bien estar bajo la amenaza de alguien que permanezca en su país de origen. Aquellas que proceden de América Latina suelen entrar por los aeropuertos de Madrid y/o Barcelona, en el caso de las paraguayas no suelen hablar castellano y piensan que van a desarrollar trabajos de cuidadoras, hostelería y/o otras profesiones en las que no se pide una especial formación. El caso de las mujeres nigerianas es diferente, la mayoría proceden del estado de Edo y la ciudad de Benin City, al sur del país, de religión cristiana mezclada con creencias animistas. En ellas el vudú tiene un peso importante. Suelen ser sometidas antes de salir de sus ciudades mediante un rito donde un brujo del pueblo elabora un paquetito con sangre menstrual, uñas, vello púbico y/o prendas íntimas. Este se le entrega al capo del que pasan a depender y al que deben satisfacer la deuda contraída. Estas mujeres piensan que mientras ellos los tengan en su poder, les puede pasar algo malo a ellas o a sus familias. En este caso suelen atravesar África, muchas veces a pie, para poder llegar con pateras a territorio español ${ }^{35}$. El último caso que se está estudiando es el de las mujeres chinas, las cuales solo suelen relacionarse con hombres de su misma nacionalidad, en pisos, nunca en la calle, muchas veces utilizando España como medio para alcanzar Gran Bretaña o Estados Unidos. Este delito, en estas mujeres, ha sido utilizado como una alternativa a la trata con fines de explotación laboral más fácil de perseguir.

33. Mabel Lozano. Proyecto «Chicas nuevas 24 horas». Acceso: 14 de febrero, 2017. http://www.proyectochicasnuevas24horas.com/. También es interesante el libro que acaba de publicar con testimonios de proxenetas y mujeres que han sido objeto de trata: El proxeneta (Barcelona: Argumentaria, 2017).

34. Véanse, entre otras, las referencias recogidas en la bibliografía de este trabajo.

35. Para mayor información, véase: Gemma Fernández Rodríguez de Liévana y Paloma Soria Montañez (coord.), La trata de mujeres y niñas nigerianas: esclavitud entre fronteras y prejuicios. Women's Link Worldwide, 2014. Acceso: 25 de abril, 2017. http://www.lrmcidii.org/wp-content/uploads/2014/04/ Women_s_Link_Trata_de_mujeres_y_ni_as_africanas.pdf 


\section{Conclusión}

Defred, el personaje que Margaret Atwood inventó en su obra «El cuento de la criada», decía en un pasaje que evitaba mirar su cuerpo no porque fuera algo vergonzoso e impúdico, sino porque no quería mirar algo que la determinase de forma tan absoluta ${ }^{36}$. Introducir elementos para la reflexión sobre las mujeres y niñas que son objeto de trata con fines de explotación sexual, es sentirse identificada con esa frase, con el sentido último que este texto hace remover en las conciencias.

Lo expuesto hasta aquí no son sino pinceladas de un problema que sigue estando en el «debe» de los poderes públicos en España y de su sociedad civil. Hay que seguir legislando, buscando aprobar la ley integral; hay que seguir denunciando y dejando actuar a las fuerzas y cuerpos de seguridad del Estado y hay que seguir concienciando y visibilizando la existencia de este delito.

Mientras se mire hacia otro lado con el tema de la prostitución y no se repudie de igual modo que se hace con la trata, ambas seguirán formando parte de una misma realidad. De la realidad de miles de mujeres y niñas, muchas de ellas menores de edad, que ven cada día cómo se vulneran y pisotean sus derechos humanos, sus necesidades más elementales, su dignidad.

Responder que «No» a la pregunta sobre si es compatible la trata y, por ende, la prostitución con un modelo de sociedad igualitaria, es el primer paso para luchar contra las redes y las mafias que explotan y convierten en esclavas a millones de mujeres en el mundo. Trabajar en la educación de aquellos que deben romper con el uso de las mujeres como mercancías, es el único mecanismo y la única tabla de salvación que a muchas de ellas aún les queda. Que en la legislación española la mujer que sea objeto de trata sea identificada como víctima de violencia de género, supondrá un paso adelante en su protección. Pero no solo eso, que la trata sea sinónimo de violencia de género, supondrá aceptar que dicho delito es consecuencia de la sociedad patriarcal y del papel secundario, supeditado y de inferioridad en el que históricamente se ha situado a las mujeres. Trabajar en su prevención, detección y sanción desde una perspectiva de género es el único medio de romper con la desigualdad, discriminación y subordinación a las que están sometidas. Como afirmaba una mujer que había conseguido salir de la trata, el oficio más antiguo del mundo no es la prostitución, como muchos se empeñan en seguir repitiendo para acreditar su existencia, sino que lo es el mirar hacia otro lado ${ }^{37}$. Y desde la Academia no se puede ni se debe permitir.

36. Margaret Atwood, El cuento de la criada (Barcelona: Narrativa Salamandra, 2017).

37. «El oficio más antiguo del mundo es seguir mirando para otro lado». Acceso: 20 de abril, 2017. http:// www.amecopress.net/spip.php?article14411 


\section{ABSTRACT}

\section{Human trafficking for sexual exploitation in Spain: elements for reflection}

Even though the Spanish legislation does not consider human trafficking for sexual exploitation gender violence, the reality is that several organizations are working towards modifying the legislation following international agreements signed and ratified by the Spanish government and with the help from civil society. It's close relationship with prostitution, the confusion between it and illegal human trafficking, and the amount of data for its quantification have made this type of trafficking a local phenomenon many people claim to be unaware of, but which is nonetheless widespread. The aim of this study is to give visibility to this problem and open spaces to reflect about it.

Key words: prostitution, slavery, sexual abuse, Spain

RÉSUMÉ

\section{La traite des personnes en vue de l'explotation sexuelle en Espagne: des éléments pour réfléchir}

Bien que la législation espagnole ne reconnaît pas la traite des personnes à des fins d'exploitation sexuelle comme violence sexiste, différentes instances sont en train de travailler pour la modifier selon les accords internationaux signès et ratifiés pour le gouvernement espagnol et les voix des groupes civiles qui s'ont lévé. À cause de son lien étroit avec la prostitution, la confusion avec le trafic illicite de personnes et le manque de clarté des données qui existe pour la quantifier, la traite de personnnes est devenu un phènomène inconnu mais qui a une présence importante dans le territoire. Ce travail a par but rend visible ce phénomène et ouvrir des espaces par sa reflexion.

Mots clès : prostitution, esclavage, violence sexuelle, Espagne.

\section{Bibliografía}

ACCEM. La Trata de personas con fines de explotación laboral. Un estudio con fines de aproximación a la realidad en España. Madrid: Secretaría de Estado de Emigración e Inmigración. 2006. Acceso: 16 de febrero, 2017. http://www.accem.es/ficheros/documentos/pdf_publicaciones/trata.pdf

Alconada de los Santos, Mercedes. Estudio sobre las mujeres víctimas de trata con fines de explotación sexual en Andalucía. Sevilla: Instituto Andaluz de la Mujer, 2011.

APRAMP (Asociación para la Prevención, Reinserción y Atención de la Mujer Prostituida). La prostitución. Claves básicas para reflexionar sobre un problema. 2005 Acceso: 18 de enero, 2017. http://apramp.org/ download/la-prostitucion-claves-para-reflexionar-sobre-un-problema/

La trata de personas con fines de explotación sexual. 2015. Acceso: 18 de enero, 2017. http:// apramp.org/download/la-trata-con-fines-de-explotacion-sexual/.

A pie de calle. Actuaciones con menores víctimas de trata. 2015. Acceso: 18 de enero, 2017. http:// apramp.org/download/a-pie-de-calle-actuaciones-con-menores-victimas-de-trata/

Atwood, Margaret. El cuento de la criada. Barcelona: Narrativa Salamandra, 2017.

Blázquez Vilaplana, Belén, «Políticas públicas en España contra la Trata de Personas: El plan integral de lucha contra la trata de seres humanos con fines de explotación sexual». Revista IXAYA (Revista Universitaria de Desarrollo Social), n. ${ }^{\circ} 6$ (2014): 41-76.

Bracamontes Ramírez, Elisabeth, «La necesidad de una ley integral contra la violencia de género en España. (LO 1/2004)». Revista La Ventana, n. ${ }^{\circ} 43$ (2016): 125-273. Acceso: 20 de marzo, 2017. https://dialnet.unirioja.es/servlet/articulo?codigo $=5586752$ 
Cacho, Lydia. Esclavas del poder. Los viajes al corazón de la trata sexual de mujeres y niñas en el mundo. Barcelona: Random House, 2014.

Christensen, Tyler Marie. Trata con fines de explotación sexual: protección de las víctimas en la legislación nacional e internacional de asilo, Informe de Investigación No 206. ACNUR, 2011. Acceso: 20 de marzo, 2017. http://www.acnur.org/t3/fileadmin/scripts/doc.php?file=biblioteca/pdf/7514

Consejo de Europa. Informe GRETA sobre España. 2013. Acceso: 15 de febrero, 2017. http://sicarcat.files.wordpress.com/2013/10/greta_2013_16_fgr_esp_public_en.pdf

Cordero Ramos, Nuria, «Trata con fines de explotación sexual. Derechos humanos que maltratan a las humanas». Gazeta de Antropología, n. ${ }^{\circ}$ 30, 3 (2014). Acceso: 12 febrero, 2018. http://www.gazeta-antropologia. $\mathrm{es} / \mathrm{p}=4627$

Cruz Zúñiga, Pilar y Cordero Ramos, Nuria, ed. Análisis, retos y propuestas en torno a la trata de personas. Sevilla: Acongagua Libro, 2014.

Delegación del Gobierno para la Violencia de Género, Ministerio de Sanidad, Servicios Sociales e Igualdad. Informes de Seguimiento y Evaluación del Primer Plan contra la Trata de Personas con Fines de Explotación Sexual. S.f. Acceso: 16 de marzo, 2017. http://www.violenciagenero.msssi.gob.es/otrasFormas/trata/normativaProtocolo/informes/home.htm

De Miguel Álvarez, Ana. Neoliberalismo sexual: el mito de la libre elección. Valencia: Cátedra, 2015.

Domínguez, Iñigo y José María Jiménez Gálvez, «Esclavos en España en el Siglo XXI». Diario El País, Reportajes Especiales, 17 al 22 de abril, 2017. Acceso: 25 de abril de 2017. http://elpais.com/agr/ esclavos_en_espana_en_el_siglo_xxi/a/

Europa Press. «Es legal la prostitución en España? Situación de la prostitución en España». Acceso: 14 de febrero, 2017, http://www.europapress.es/sociedad/noticia-situacion-prostitucion-espana-20150421141927. html

Federación de Mujeres Progresistas, ed. Trata de mujeres con fines de explotación sexual en España (estudio exploratorio). Madrid: Agencia Española de Cooperación Internacional, 2008.

Fernández Rodríguez de Liévana, Gemma y Paloma Soria Montañez (coord.). La trata de mujeres y niñas nigerianas: esclavitud entre fronteras y prejuicios. Women's Link Worldwide, 2014. Acceso: 25 de abril, 2017. http://www.lrmcidii.org/wp-content/uploads/2014/04/Women_s_Link_Trata_de_mujeres_y_ni_as_africanas.pdf

Fuentes, Teo y Gino Ochoa. «La Ley Mordaza olvida que las prostitutas también son personas». Diagonal Periódico, 28 de agosto, 2015. Acceso: 14 de enero, 2017. https:/www.diagonalperiodico.net/ andalucia/27601-la-ley-mordaza-se-olvida-prostitutas-tambien-son-ciudadanas.html

García Sánchez, Esther, «La génesis de la política del gobierno central contra la violencia de género en España: ideas, prioridades y policy changes». En Igualdad de género y no discriminación en España: evolución, problemas y perspectivas. Madrid: Centro de Estudios Políticos y Constitucionales, 2016.

Gobierno de España. Plan Integral de lucha contra la trata de personas con fines de explotación sexual 20092012. Madrid: Ministerio de Sanidad, Servicios Sociales e Igualdad, 2010.

Gobierno de España. Plan Integral de lucha contra la trata de personas con fines de explotación sexual 2015 2018. Ministerio de Sanidad, Servicios Sociales e Igualdad, 2016.

Gómez Suárez, Águeda, Silvia Pérez Freire y Rosa María Verdugo Matés. El putero español. Quiénes son y qué buscan los clientes de la prostitución. Madrid: Catarata, 2015.

López, Gloria. «El oficio más antiguo del mundo es seguir mirando para otro lado». Acceso: 20 de abril, 2017. http://www.amecopress.net/spip.php?article14411 
Lorente Acosta, Miguel. Mi marido me pega lo normal. Barcelona: Crítica, 2003.

Lozano, Mabel. El proxeneta. Barcelona: Argumentaria, 2017.

Martín-Arroyo, Javier, «Denunciados un millar de prostitutas y clientes tras un año de la "Ley Mordaza"». Diario El País. Acceso: 20 de febrero, 2017. http://politica.elpais.com/politica/2016/09/02/actualidad/1472839814_078043.html

Mena Martínez, Luis, «Los números de la trata de personas en España». Revista Documentación Social, n. ${ }^{\circ} 159$ (2010): 119-145.

Meneses Falcón, Carmen (coord.), Jorge Uroz, Antonio Rúa, Cristina Gortazar y Ma José Castaño, Apoyando a las víctimas de trata. Las necesidades de las mujeres víctimas de trata con fines de explotación sexual desde la perspectiva de las entidades especializadas y profesionales involucrados. Propuesta a la sensibilización de la trata. Madrid: Delegación del Gobierno para la Violencia de Género. Ministerio de Sanidad, Servicios Sociales e Igualdad, 2015.

Nuño Gómez, Laura, «La trata de seres humanos con fines de explotación sexual: propuestas para un cambio de paradigma en la orientación de las políticas públicas». Revista de Derecho Político. UNED n. ${ }^{\circ} 98$, enero-abril (2017): 159-187.

Nuño Gómez, Laura (Dir); Ana De Miguel Álvarez (Dir). Elementos para una teoría crítica del sistema prostitucional. Granada: Comares, 2017.

Oficina de las Naciones Unidas contra la Droga y el Delito. Informe Mundial sobre la trata de personas. Resumen Ejecutivo, 2014. Acceso: 20 de abril, 2017. https://www.unodc.org/documents/data-and-analysis/ glotip/GLOTIP14_ExSum_spanish.pdf

Requena Espada, Laura, Andrea Giménez-Salinas Framis y Manuel de Juan Espinosa. «Estudiar la trata de personas. Problemas metodológicos y propuestas para su resolución». Revista Electrónica de Ciencia Penal y Criminológica. 14-13 (2012). Acceso: 10 de febrero, 2017. http://criminet.ugr.es/recpc/14/recpc14-13.pdf

Torres Reyes, Alejandro. «Unas 45000 mujeres y niñas son víctimas de trata en España». Diario El País. 18 de septiembre, 2015. Acceso: 15 de febrero, 2017. http://politica.elpais.com/politica/2015/09/18/actualidad/1442572111_462915.html

UNICEF. Trata de personas. Una forma de esclavitud moderna. Argentina: Ministerio de Justicia y Derechos Humanos de la Nación, 2014.

Son niños y niñas, son víctimas. Situación de los menores de edad víctimas de trata en España. Acceso: 15 de febrero, 2017. https://www.unicef.es/sites/unicef.es/files/comunicacion/ninos-victimas.pdf

UNODC. Global report on trafficking in persons 2016. Acceso: 15 de febrero, 2017. http://www.unodc.org/unodc/data-and-analysis/glotip.html

Varela, Nuria. Íbamos a ser reinas: mentiras y complicidades que sustentan la violencia contra las mujeres. Barcelona: Ediciones B, 2002.

Nuria. La voz ignorada. Ana Orantes y el fin de la impunidad. Colección Endebate, 2012.

\section{Normativa}

Acuerdo del Pleno No Jurisdiccional de la Sala Segunda del Tribunal Supremo de 31-05-2016, sobre si el delito de trata de seres humanos definido en el art. 177 bis del Código Penal, dentro del Título VII bis del Libro II, últimamente reformado por la LO 1/2015, de 30 de marzo, con entrada en vigor el día 1 de julio de 2015, toma en consideración un sujeto pasivo plural, o bien han de ser sancionadas tantas conductas cuantas personas se vean involucradas en la trata como víctimas del mismo. 
Convención sobre la Eliminación de todas las Formas de Discriminación contra la mujer. Naciones Unidas. 1979.

Convenio del Consejo de Europa sobre prevención y lucha contra la violencia contra las mujeres y la violencia doméstica (Convenio de Estambul). 2011.

Convenio del Consejo de Europa sobre la lucha contra la trata de personas. 2005 (ratificado por España en 2009).

Declaración sobre la eliminación de la violencia contra la mujer de la Asamblea General de las Naciones Unidas. 1999.

Estrategia de la Unión Europea para la Erradicación de la Trata de Seres Humanos (2012-2016).

Ley Orgánica10/1995, de 23 de noviembre, del Código Penal.

Ley Orgánica 1/2004, de 28 de diciembre, de Medidas de Protección Integral contra la Violencia de Género.

Ley Orgánica 4/2015, de 30 de marzo, de protección de la seguridad ciudadana.

Ley Orgánica 3/2007, de 22 de marzo, de Igualdad Efectiva entre Mujeres y Hombres.

Ley Orgánica 5/2010, de 22 de junio, por la que se modifica la Ley Orgánica 10/1995, de 23 de noviembre, del Código Penal.

Ley Orgánica 1/2015, de 30 de marzo, por la que se modifica la Ley Orgánica 10/1995, de 23 de noviembre, del Código Penal.

Protocolo para Prevenir, Reprimir y Sancionar la trata de personas que complementa la Convención de Naciones Unidas contra la Delincuencia Organizada Transnacional (Nueva York 2000) BOE n. ${ }^{\circ} 296$, de 11 de diciembre, 2003.

Resolución de la Comisión de Derechos Humanos 2005/41 (Oficina del Alto Comisionado de las Naciones Unidas para el Desarrollo Humano).

Resolución 64/293 de la Asamblea General de las Naciones Unidas (Plan de Acción Mundial de las Naciones Unidas para combatir la trata de Personas), 12 de agosto, 2010. 